\title{
Interaction of 2,2,2-trifluoroethanol with proteins: calorimetric, densimetric and surface tension approach
}

\author{
Agnita Kundu, Nand Kishore* \\ Department of Chemistry, Indian Institute of Technology Bombay, Powai, Mumbai - 400 076, India
}

\begin{abstract}
The thermal denaturation of hen egg-white lysozyme was studied in the presence of 2,2,2-trifluoroethanol (TFE) at various $\mathrm{pH}$ values using micro differential scanning calorimetry. Quantitative thermodynamic parameters accompanying the thermal transitions were evaluated. It is observed that thermal unfolding of lysozyme in the presence of TFE upto a concentration of $4.0 \mathrm{~mol} \mathrm{dm}{ }^{-3}$ follows a two-state denaturation mechanism as indicated by the equality of van't Hoff and calorimetric enthalpies. The finer details of interaction were studied by measuring the partial molar volume of some constituent amino acids and glycine peptides from water to aqueous TFE at $298.15 \mathrm{~K}$. The physicochemical properties of aqueous TFE: apparent molar heat capacities, apparent molar volumes and surface tension were measured to understand the intrinsic properties of the cosolvent as well. From the correlation among the thermal unfolding data on lysozyme in aqueous TFE, calculated preferential interaction parameters, physico chemical properties of aqueous TFE and partial molar volumes of transfer, it is concluded that both solvent mediated effect and direct interaction constitute the mechanism of TFE-protein interactions.
\end{abstract}

Keywords: 2,2,2-Trifluoroethanol; Lysozyme; Differential scanning calorimetry; Partial molar heat capacity; Partial molar volume; Preferential interaction parameters

\section{Introduction}

The trapping and characterization of the partially folded states is essential in elucidating the question of how a linear chain of amino acid of protein folds itself to the three-dimensional unique configuration. 2,2,2-Trifluoroethanol (TFE) was first used [1] in 1962, to generate these partially folded states. Ever since then, use of this alcohol has been extensive because of its efficiency to generate the partially folded states of proteins [2-5], amongst which, many are molten globule [6-8] which are found as intermediates in the protein folding pathways [9]. All the normal and substituted alcohols have been observed to generate these partially folded states by helix induction $[10,11]$. Not only helical structures, but also the TFE were found to stabilize $\beta$-sheets and $\beta$ hairpins [12]. In view of the above facts it is important to understand the mechanism by which TFE generates partially folded states in proteins. 
There are some common points in the action of TFE with proteins. TFE does not induce secondary structures indiscriminately, rather the regions in the polypeptide chain or proteins that are helical in the native state or have a strong sequence propensity to adopt helical comformation are stabilized preferentially [13]. Aqueous TFE at 5-15 mol\% has been reported to produce similar results for a variety of physicochemical phenomena, including helicity in polypeptides [14]. At very high concentrations of TFE, the influence of the hydrophobic trifluoromethyl group increases the hydrophobic exposure, disrupting the tertiary structure [15]. At high concentrations of TFE (above $40 \%$ ) the composition of the solvent becomes less like bulk water and more like bulk alcohol. The mechanism proposed for the helix inducing ability of TFE is either helix stabilization by direct binding of TFE to the peptides [16-19] or in which the effect of TFE is solvent mediated, i.e. by causing some changes in the surrounding solvent, which in turn affect the protein structure in water $[14,20]$. Thus the mode of interaction of TFE with proteins is not yet clear and requires an experimental proof.

Keeping this in mind, we attempted to explore the thermal unfolding of protein in the presence of TFE and the mechanism of TFE interaction with protein. The protein chosen was hen eggwhite lysozyme (hew lysozyme) as it is well characterized with known amino acid sequence and well established crystal structure [21]. The interaction of TFE with lysozyme has been studied qualitatively by spectroscopic approach, $[2,8,22-$ $24]$ and there is a need to obtain quantitative data on the thermal unfolding of the protein in presence of TFE. To study the finer details of interaction of TFE with proteins, it is also necessary to understand the physicochemical properties of waterTFE mixture and its interaction with the constituent groups of the protein as the macromolecule itself is complex. The apparent molar volumes of some amino acids and peptides in aqueous $1 \mathrm{~mol} \mathrm{dm}^{-3}$ TFE were determined and their partial molar volumes of transfer from water to $1 \mathrm{~mol}$ $\mathrm{dm}^{-3}$ TFE were calculated. Apparent molar heat capacities and apparent molar volumes of TFEwater mixture were determined over a wide range of molality and temperature. The surface tension of aqueous TFE was determined at $298.15 \mathrm{~K}$. Lastly, the results on thermal denaturation of lysozyme in the presence of TFE, apparent molar heat capacity and apparent molar volume of aqueous TFE, volume of transfer of some amino acids and

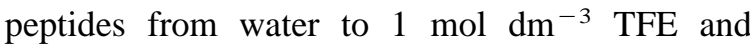
surface tension of TFE have been correlated to discuss the mode of interaction of TFE with proteins.

\section{Experimental methodology}

\subsection{Materials}

Hen egg-white lysozyme, glycine, L-serine, Laspartic acid, L-valine, L-lysine, diglycine, triglycine and 2,2,2-triflulroethanol of the best available purity grade were purchased from Sigma Chemical Company, USA and used without further purification. The mass fraction purity of TFE checked by gas chromatography was 0.99. A Sartorius BP 211D digital balance of readability $\pm 0.01 \mathrm{mg}$ was used for the mass measurements. The moisture content in the alcohol, amino acids and peptides was determined by Karl Fischer titration and dry weights of the samples were corrected wherever necessary. The temperature of the balance, atmospheric pressure and humidity in the laboratory were determined daily, which were used to calculate the density of air with the formulae given by Jones [25]. The water used for preparing solutions was double distilled followed by de-ionization by passing it through Cole-Parmer Research Ion Exchanger and degassed before preparing solutions for calorimetric, densimetric and surface tension measurements.

\subsection{Differential scanning calorimetry}

The thermal denaturation experiments were carried out on a micro DSC from SETARAM, France. For thermal denaturation experiments, lysozyme was dialyzed at $277 \mathrm{~K}$ against $20 \times 10^{-3} \mathrm{~mol}$ $\mathrm{dm}^{-3}$ buffer at the desired $\mathrm{pH}$ determined on a Standard Control Dynamics $\mathrm{pH}$ meter at room temperature. The protein concentration was kept at $0.214 \times 10^{-3} \mathrm{~mol} \mathrm{dm}^{-3}$ and scan rate used in 
all the experiments was $30 \mathrm{~K} \mathrm{~h}^{-1}$. Experimental details and procedure for conversion of the raw data to excess heat capacity vs. temperature plots have been reported earlier in Ref. [26]. The excess heat capacity vs. temperature plots were analyzed by the EXAM program of Kirchhoff [27] and the thermodynamic parameters accompanying the thermal transitions were evaluated. The reversibility of the scans was checked by heating the sample to just above transition temperature, cooling immediately and then reheating. The thermal denaturation of hen egg-white lysozyme in the presence of varying concentrations of TFE was performed at $\mathrm{pH} 2.4,3.1$ and 4.0. The buffers used were glycine$\mathrm{HCl}$ at $\mathrm{pH} 2.4$ and 3.1, and acetate at $\mathrm{pH}$ 4.0. The concentration of the protein was determined spectrophotometrically on a Shimadzu double-beam spectrophotometer UV 220 using extinction coefficient corresponding to $E_{280}^{1 \%}=26.3$ [24].

The heat capacities of aqueous TFE prepared in de-ionized and degassed water were also measured on a micro differential scanning calorimeter employing the sealed vessels of $1 \mathrm{~cm}^{3}$ volume. The instrument has a heat capacity resolution of $5 \times 10^{-5}$ of the absolute value. In order to minimize the vapor space in the measuring cell, the level of the liquid was always kept at approximately $98 \%$ of the total volume of the cell. The weights of the sample and reference cell with or without the liquid of interest were always matched to $<0.1 \mathrm{mg}$. The apparent molar heat capacities of aqueous TFE in the molality range of 0.08709$5.25634 \mathrm{~mol} \mathrm{~kg}^{-1}$ were determined on DSC at a scant rate of $12 \mathrm{~K} \mathrm{~h}^{-1}$ from 298.15 to $328.15 \mathrm{~K}$. The method of calculation of heat capacity from the instrumental output has been described earlier [28].

\subsection{Densimetry}

The measurements of densities were done on a DA 210 digital densitometer purchased from Kyoto Electronics, Japan. A Julabo constant temperature circulator was used to control the temperature of the densitometer cell. The temperature stability of the water around the cell was $\pm 0.01 \mathrm{~K}$. The calibration of the densitometer was checked daily by measuring the values of apparent molar volume of aqueous sodium chloride and comparing with the literature values [29], which had an excellent agreement. The values of apparent molar volume of aqueous TFE were determined at 283.11, $288.11,298.15$ and $308.19 \mathrm{~K}$ over a wide range of molality of the alcohol (0.02364-1.04597 mol $\left.\mathrm{kg}^{-1}\right)$. The values of apparent molar volume of amino acids and glycine peptides in $1 \mathrm{~mol} \mathrm{dm}^{-3}$ TFE were determined at $298.15 \mathrm{~K}$. The method of operation of the densitometer and calculation of the apparent molar volume from density data has been described earlier [28].

\subsection{Surface tension measurements}

Surface tension measurements of TFE-water mixtures were carried out by the drop weight method [30]. A Cole-Parmer constant temperature circulator was employed to circulate water through the glass jacket around the stalagmometer for achieving the desired temperature. The control of the temperature thus obtained was within \pm 0.02 $\mathrm{K}$. For surface tension measurements, the molality range of the alcohol covered was from 0.10002 to $2.02139 \mathrm{~mol} \mathrm{~kg}^{-1}$ at $298.15 \mathrm{~K}$.

\section{Results ${ }^{1}$}

3.1. Differential scanning calorimetric study of lysozyme in presence of TFE at pH 2.4, 3.1 and 4.0

The thermal denaturation of lysozyme in presence of TFE was studied as a function of $\mathrm{pH}$ to examine the charge effect on the alcohol-protein interactions. The thermodynamic parameters accompanying the thermal transitions are given in Table 1.

With an increase in $\mathrm{pH}$ from 2.4 to 4.0 , the denaturation temperature of lysozyme varies nonlinearly in the absence and presence of TFE (Fig. 1). These $\mathrm{pH}$ values were chosen because above pH 6.0 lysozyme oligomerises. Since the transition temperature changes with change in $\mathrm{pH}$, the extent of abstraction and release of protons to the amino acid side chains of the protein $(\Delta \nu)$ was calculated

\footnotetext{
${ }^{1}$ The table and figure number with prefix $S$ are given in the supporting information section.
} 
Table 1

Thermodynamic parameters associated with the thermal unfolding of $0.25 \mathrm{mM}$ lysozyme in $20 \mathrm{mM}$ glycine- $\mathrm{HCl}$ buffer at $\mathrm{pH} 2.4$ in presence of TFE at different $\mathrm{pH}$ values ${ }^{\dagger}$

\begin{tabular}{|c|c|c|c|c|c|}
\hline $\begin{array}{l}\text { Cosolvent/ } \\
\mathrm{mol} \mathrm{dm}^{-3}\end{array}$ & $\begin{array}{l}T_{1 / 2} \\
(\mathrm{~K})\end{array}$ & $\begin{array}{l}\Delta H_{\mathrm{cal}} \\
\left(\mathrm{kJ} \mathrm{mol}{ }^{-1}\right)\end{array}$ & $\begin{array}{l}\Delta C_{P} \\
\left(\mathrm{~kJ} \mathrm{~K}^{-1} \mathrm{~mol}^{-1}\right)\end{array}$ & $\begin{array}{l}\Delta S \\
\left(\mathrm{~kJ} \mathrm{~K}^{-1} \mathrm{~mol}^{-1}\right)\end{array}$ & $\begin{array}{l}\beta \\
\left(\Delta H_{\mathrm{vH}} / \Delta H_{\mathrm{cal}}\right)\end{array}$ \\
\hline \multicolumn{6}{|l|}{$\mathrm{pH}=2.4$} \\
\hline 0.0 & 336.4 & 440 & 4.5 & 1.308 & 1.02 \\
\hline 1.0 & 330.7 & 419 & 3.7 & 1.267 & 1.03 \\
\hline 2.0 & 320.5 & 380 & 2.6 & 1.187 & 0.98 \\
\hline 3.0 & 309.3 & 297 & 2.8 & 0.960 & 0.97 \\
\hline \multicolumn{6}{|l|}{$\mathrm{pH}=3.1$} \\
\hline 0.0 & 347.1 & 495 & 5.6 & 1.426 & 1.01 \\
\hline 1.0 & 341.2 & 488 & 4.2 & 1.430 & 1.04 \\
\hline 2.0 & 331.9 & 437 & 3.5 & 1.317 & 0.99 \\
\hline 3.0 & 319.9 & 331 & 2.9 & 1.035 & 0.99 \\
\hline 4.0 & 309.2 & - & 4.8 & - & 1.02 \\
\hline \multicolumn{6}{|l|}{$\mathrm{pH}=4.0$} \\
\hline 0.0 & 351.2 & 513 & 5.2 & 1.461 & 1.02 \\
\hline 1.0 & 344.4 & 484 & 3.7 & 1.405 & 1.03 \\
\hline 2.0 & 334.7 & 437 & 3.5 & 1.306 & 0.98 \\
\hline 4.0 & 310.7 & 262 & 4.6 & 1.186 & 0.99 \\
\hline
\end{tabular}

${ }^{\dagger}$ The $T_{1 / 2}$ (temperature at which transition is half complete) values have an experimental error of $\pm 0.1 \mathrm{~K}$ and the $\Delta H_{\text {cal }}$ (calorimetric enthalpy), $\Delta S$ (entropy), and $\Delta C_{P}$ (heat capacity) of unfolding have an experimental error of $2 \%$, including error in sample preparation, calibration constant and reproducibility of the measurements.

[31] by using:

$\Delta v=-\frac{\Delta H_{\mathrm{cal}}\left(T_{1 / 2}\right)}{2.303 R T_{1 / 2}^{2}} \frac{\mathrm{d} T_{1 / 2}}{\mathrm{~d} p H}$.

The calculated values of $\Delta \nu$ are given in Table 2 .

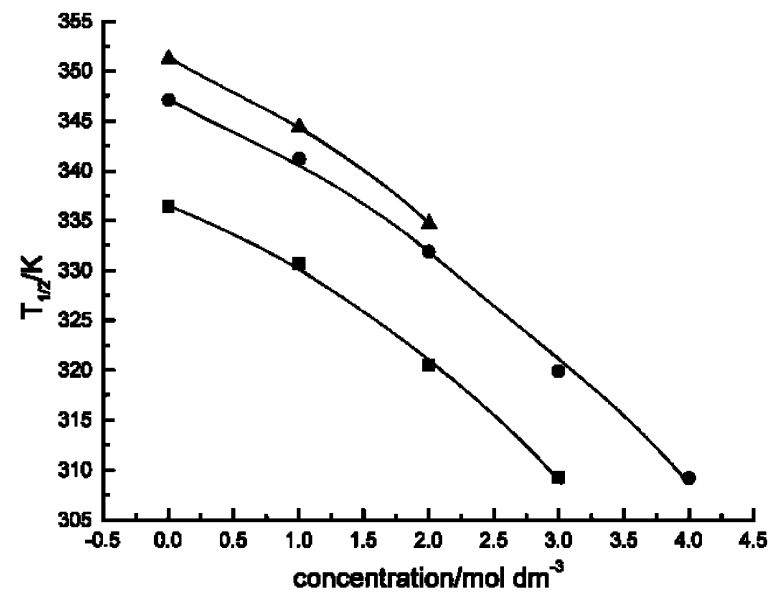

Fig. 1. The temperature of denaturation of lysozyme as a function of $\mathrm{pH},(\boldsymbol{\Delta}) 2.4$; $(\mathbf{\bullet}) 3.1$; $(\bullet) 4.0$.
When the native protein denatures, its surface changes its character, hence the preferential solvation of the macromolecule by the surrounding solvent also changes. Preferential solvation is a purely thermodynamic characteristic of the interactions of a macromolecule with solution components, which can be calculated by measuring the changes of this quantity for conformational transitions in proteins. The denaturational change in the preferential solvation parameter $\left(\Delta \Gamma_{23}\right)$ of component 2 (protein) by component 3 (cosolvent) was calculated by using the following equation [32]:

Table 2

The denaturational increase in the number of protons $(\Delta \nu)$ upon unfolding of lysozyme at different $\mathrm{pH}$ values

\begin{tabular}{lll}
\hline Concentration of TFE & $\mathrm{pH}$ & $\Delta \nu$ \\
\hline 0 & 2.4 & 4.1 \\
& 3.1 & 2.3 \\
1 & 2.4 & 4.1 \\
2 & 3.1 & 2.2 \\
& 2.4 & 4.2 \\
& 3.1 & 2.2 \\
\hline
\end{tabular}




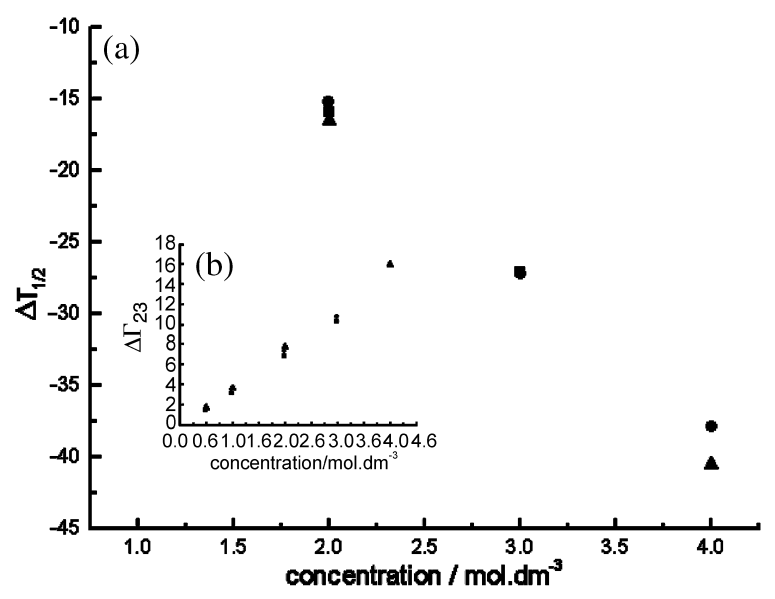

Fig. 2. (a) The plot of $\Delta T_{1 / 2}\left(T_{1 / 2}\right.$ in alcohol $-T_{1 / 2}$ in buffer $)$ against the concentration of TFE at $\mathrm{pH}(\boldsymbol{\square}) 2.4,(\mathbf{O}) 3.1,(\mathbf{\Delta})$

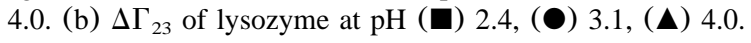

$$
\Delta \Gamma_{23}=\Gamma_{\mathrm{D} 3}-\Gamma_{\mathrm{N} 3}=-\frac{\Delta H\left(\frac{\partial T_{1 / 2}}{\partial x_{3}}\right)_{\mathrm{pH}}}{R T_{1 / 2}^{2}\left(\frac{\partial \ln a_{3}}{\partial x_{3}}\right)_{T_{1 / 2}}}
$$

where $\Gamma_{\mathrm{D} 3}$ and $\Gamma_{\mathrm{N} 3}$ are the preferential solvation parameters of the protein by alcohol in the denatured and native state, respectively. Here $x$ and $a$ are the mole fraction and activity of TFE, respectively. The maximum mole fraction of TFE in this study was 0.085 , hence the activity coefficient was considered to be unity at this low concentration. The plot of $\Delta \Gamma_{23}$ as a function of TFE concentration is given in Fig. $2 \mathrm{~b}$ at three different $\mathrm{pH}$ values.

\subsection{Apparent molar volumes of amino acids and peptides in $1 \mathrm{~mol} \mathrm{dm}^{-3} \mathrm{TFE}$}

To understand the fine details of the interaction of TFE with the constituent groups of the protein, we have determined the partial molar volumes of transfer of some amino acids and peptides from water to $1 \mathrm{~mol} \mathrm{dm}^{-3} \mathrm{TFE}$ at $298.15 \mathrm{~K}$. The densities and apparent molar volumes of amino acids, glycine, L-serine, L-valine, L-lysine and Laspartic acid at $298.15 \mathrm{~K}$ are presented in Table $\mathrm{S} 1$. The reason for choosing these amino acids is their diverse nature. Glycine is the simplest of the amino acids. Serine is a polar amino acid due to the presence of $-\mathrm{CH}_{2} \mathrm{OH}$ group. Valine is hydrophobic due to $-\mathrm{CH}\left(\mathrm{CH}_{3}\right)_{2}$ group, lysine is positively charged with a long hydrophobic chain attached to it and aspartic acid is negatively charged with one $-\mathrm{CH}_{2}$ group, making it less hydrophobic than lysine or valine. In the case of serine and valine no clear molality dependence in the values of the apparent molar volume was observed, hence their average was taken as the partial molar volume. However, for the other amino acids and peptides studied, the apparent molar volume $V_{\phi, 2}$ was found to be a linear function of the molality over the molality range studied. In these cases, the values of standard partial molar volume $V_{2, m}^{\mathrm{o}}$ were obtained by leastsquares fitting to the following equation:

$V_{\phi, 2}=V_{2, m}^{\mathrm{o}}+S_{v} m$

Here, $S_{v}$ is the experimental slope which is sometimes considered to be a volumetric pairwise interaction coefficient [33]. The $S_{v}$ values for glycine, aspartic acid and lysine are $0.80 \pm 0.08$, $4.65 \pm 0.70$ and $7.06 \pm 0.89 \mathrm{~cm}^{3} \mathrm{~mol}^{-2} \mathrm{~kg}$, respectively.

The values of partial molar volume of transfer of amino acids and peptides from water to $1 \mathrm{~mol}$ $\mathrm{dm}^{-3}$ TFE were calculated as below:

$$
\begin{aligned}
V_{2, m}^{\mathrm{o}}(\mathrm{tr})= & V_{2, m}^{\mathrm{o}}(\text { compound } \\
& \left.+1 \mathrm{~mol} \mathrm{dm}^{-3} \mathrm{TFE}\right) \\
& -V_{2, m}^{\mathrm{o}}(\text { compound }+ \text { water }),
\end{aligned}
$$

and the corresponding transfer parameters are given in Table 3. The partial molar volumes of the amino acids and glycine peptides in water were taken from literature [34]. Since the partial molar volume or the infinite dilution apparent molar volume is free from the solute-solute interactions, $V_{2, m}^{\mathrm{o}}(\mathrm{tr})$ provides the information regarding solutesolvent interactions.

\subsection{Physico chemical properties of aqueous TFE}

In order to understand the cosolvent-protein interaction, it is further important to understand 
Table 3

Infinite dilution partial molar volumes of transfer $\left(V_{2, \mathrm{~m}, \mathrm{rr}}^{\mathrm{o}}\right)$ of some amino acids and peptides from water to $1 \mathrm{~mol} \mathrm{dm}^{-3} 2,2,2-$ trifluoroethanol at $298.15 \mathrm{~K}^{\#}$

\begin{tabular}{lccc}
\hline Compound & $\begin{array}{l}V_{2 m}^{\mathrm{o}} \\
(\text { water })\end{array}$ & $\begin{array}{l}V_{2 m}^{\mathrm{o}} \\
\left(1 \mathrm{~mol} \mathrm{dm}^{-3} \mathrm{TFE}\right)\end{array}$ & $\begin{array}{l}V_{2, m, \text { tr }}^{\mathrm{o}} \\
\left(\text { water } \rightarrow 1 \mathrm{~mol} \mathrm{dm}{ }^{-3} \mathrm{TFE}\right)\end{array}$ \\
\hline Glycine & $43.19(0.02)$ & $43.63(0.06)$ & $0.44(0.16)$ \\
Serine & $60.62(0.05)$ & $61.07(0.25)$ & $0.45(0.38)$ \\
Valine & $90.79(0.01)$ & $89.20(0.21)$ & $-1.59(0.48)$ \\
Aspartic acid & $74.80(0.20)$ & $74.09(0.11)$ & $-0.71(0.36)$ \\
Lysine & $125.93(0.09)$ & $123.09(0.31)$ & $-2.84(0.32)$ \\
Diglycine & $76.23(0.03)$ & $77.12(0.13)$ & $0.89(0.13)$ \\
Triglycine & $112.11(0.03)$ & $114.68(0.23)$ & $2.57(0.15)$
\end{tabular}

\# Entries in parentheses are standard deviations. Values of partial molar volume $\left(V_{2, m}^{\mathrm{D}}\right)$ in water have been taken from literature [34].

physico-chemical properties of the aqueous cosolvent as a function of molality and temperature. The values of apparent molar heat capacities of aqueous TFE at various temperatures and molalities are given in Table 4 and are shown in Fig. $\mathrm{S} 1$. The values of $C_{p, \phi, 2}$ are positive at all molalities and temperatures studied, which is due to the water structure making abilities of TFE [35]. At a given temperature, it is observed that the values of $C_{p, \phi, 2}$ do not show any appreciable variation with an increase in the molality of TFE up to $1.57806 \mathrm{~mol} \mathrm{~kg} \mathrm{~kg}^{-1}$, beyond which there is a decrease. Therefore, the partial molar heat capacity of aqueous TFE has been taken as the average of the $C_{p, \phi, 2}$ values upto a molality of $1.57806 \mathrm{~mol}$ $\mathrm{kg}^{-1}$. The values of measured densities and calculated apparent molar volumes of aqueous TFE at four temperatures are reported in Table S2. No clear molality dependence in values of $V_{\phi, 2}$ of TFE in water was observed in the studied molality range.

The partial molar volume and partial molar heat capacity data were fitted to Taylor expansion and the fitting coefficients are given in Table 5. Assuming the validity of group additivity scheme and using the following equation,

$$
\begin{aligned}
C_{p, 2, m}^{\mathrm{o}}(-\mathrm{F})= & 1 / 3\left[C_{p, 2, m}^{\mathrm{o}}(\mathrm{TFE})\right. \\
& \left.-C_{p, 2, m}^{\mathrm{o}}(\text { Ethanol })+3 C_{p, 2, m}^{\mathrm{o}}(-\mathrm{H})\right]
\end{aligned}
$$

the contribution of $-\mathrm{F}$ to the value of $C_{p, 2, m}^{\mathrm{o}}$ was

Table 4

\begin{tabular}{|c|c|c|c|c|c|c|c|}
\hline \multirow[t]{3}{*}{$m\left(\mathrm{~mol} \mathrm{~kg}^{-1}\right)$} & \multicolumn{7}{|c|}{$C_{p, \phi, 2} /\left(\mathrm{J} \mathrm{K}^{-1} \mathrm{~mol}^{-1}\right)$} \\
\hline & \multicolumn{7}{|l|}{$T / \mathrm{K}$} \\
\hline & 298.15 & 303.15 & 308.15 & 313.15 & 318.15 & 323.15 & 328.15 \\
\hline 0.087090 & 331 & 326 & 324 & 320 & 316 & 311 & 313 \\
\hline 0.467520 & 329 & 325 & 323 & 317 & 316 & 314 & 312 \\
\hline 0.540882 & 326 & 323 & 321 & 319 & 317 & 314 & 312 \\
\hline 1.070000 & 329 & 325 & 323 & 321 & 318 & 316 & - \\
\hline 1.578060 & 330 & 326 & 324 & 320 & 316 & 313 & - \\
\hline 2.573170 & 323 & 318 & 313 & 308 & 302 & 298 & 294 \\
\hline 3.977140 & 303 & 298 & 292 & 287 & 282 & 279 & - \\
\hline 5.256340 & 281 & 277 & 273 & 270 & 266 & 265 & - \\
\hline
\end{tabular}

Apparent molar heat capacities $\left(C_{p, \phi, 2}\right)$ of aqueous 2,2,2-trifluoroethanol

\footnotetext{
* Including the errors due to sample impurities, instrumental effect and molality determination, we assign a maximum error of $2 \%$ to the values of heat capacities in these measurements.
} 
Table 5

Fitting coefficients of the Taylor expansion series for the apparent molar heat capacity and apparent molar volume ${ }^{\mathrm{a}}$

\begin{tabular}{llll}
\hline $\begin{array}{l}\text { Temperature } \\
(\mathrm{K})\end{array}$ & $\begin{array}{l}C_{p, 2, m}^{\mathrm{o}} \\
\left(\mathrm{J} \mathrm{K}^{-1} \mathrm{~mol}^{-1}\right)\end{array}$ & $\begin{array}{l}\left(\partial C_{p, 2, m}^{\mathrm{o}} / \partial T\right)_{p} \\
\left(\mathrm{~J} \mathrm{~K}^{-2} \mathrm{~mol}^{-1}\right)\end{array}$ & $\begin{array}{l}\left(\partial^{2} C_{p, 2, m}^{\mathrm{o}} / \partial T^{2}\right)_{p} \\
\left(\mathrm{~J} \mathrm{~K}^{-3} \mathrm{~mol}^{-1}\right)\end{array}$ \\
\hline 298.15 & $330 \pm 1$ & $-0.6229 \pm 0.1412$ & $-0.0114 \pm 0.0054$ \\
303.15 & $327 \pm 1$ & $-0.6800 \pm 0.0904$ & $-0.0114 \pm 0.0054$ \\
308.15 & $324 \pm 1$ & $-0.7371 \pm 0.0480$ & $-0.0114 \pm 0.0054$ \\
313.15 & $320 \pm 1$ & $-0.7943 \pm 0.0480$ & $-0.0114 \pm 0.0054$ \\
318.15 & $316 \pm 1$ & $-0.8514 \pm 0.0904$ & $-0.0114 \pm 0.0054$ \\
323.15 & $311 \pm 1$ & $-0.9086 \pm 0.1412$ & $-0.0114 \pm 0.0054$ \\
& $V_{2, m}^{\mathrm{o}}$ & $\left(\partial V_{2, m}^{\mathrm{o}} / \partial T\right)_{p}$ & $\left(\mathrm{~cm}^{3} \mathrm{~K}^{-1} \mathrm{~mol}^{-1}\right)$ \\
283.15 & $\left(\mathrm{~cm}^{3} \mathrm{~mol}^{-1}\right)$ & $0.0754 \pm 0.0033$ & \\
288.15 & $64.79 \pm 0.05$ & $0.0778 \pm 0.0037$ & \\
298.15 & $65.12 \pm 0.04$ & $0.0754 \pm 0.0033$ & \\
308.15 & $65.92 \pm 0.03$ & $0.0754 \pm 0.0033$ & \\
\hline
\end{tabular}

${ }^{\mathrm{a}} C_{p, 2, m}^{\mathrm{o}}$, and $V_{2, m}^{\mathrm{o}}$ are partial molar heat capacity and partial molar volume of aqueous TFE.

calculated at $298.15 \mathrm{~K}$ as $63 \pm 5 \mathrm{~J} \mathrm{~K}^{-1}$. By a similar method the contribution of $-\mathrm{F}$ to the value of $V_{\phi, 2}^{\mathrm{o}}$ of aqueous TFE is calculated to be $14.11 \pm 0.76 \mathrm{~cm}^{3} \mathrm{~mol}^{-1}$. The values of $C_{p, 2, m}^{\mathrm{o}}$ and $V_{2, m}^{\mathrm{o}}$ of ethanol used were $268 \mathrm{~J} \mathrm{~K}^{-1} \mathrm{~mol}^{-1}$ [36] and $55.08 \pm 0.07 \mathrm{~cm}^{3} \mathrm{~mol}^{-1}$ [37], respectively. The contribution of $-\mathrm{H}$ to $C_{p, 2, m}^{\mathrm{o}}$ and $V_{2, m}^{\mathrm{o}}$ used was $42 \pm 1 \mathrm{~J} \mathrm{~K}^{-1} \mathrm{~mol}^{-1}$ [37] and $10.53 \pm 0.30$ $\mathrm{cm}^{3} \mathrm{~mol}^{-1}$ [7], respectively.

The excess partial molecular volume $\left(v_{2, \mathrm{ex}}^{\mathrm{o}}\right)$ per molecule is defined as

$v_{2, \mathrm{ex}}^{\mathrm{o}}=v_{2}^{\mathrm{o}}-v_{2}$

where $v_{2}^{\mathrm{o}}=V_{2}^{\mathrm{o}} / N_{\mathrm{A}}$ is partial molecular volume and $v_{2}=M_{2} /\left(N_{\mathrm{A}} d_{2}\right)$ is molecular volume, $N_{\mathrm{A}}$ is Avogadro number and $d_{2}$ is density of the pure liquid. The values of excess partial molecular volume, $v_{2, \text { ex }}^{\mathrm{o}}$ at various temperatures are given in Table 6. Although the values of $v_{2}^{o}$ and $v_{2}$ are positive and increases with an increase in the temperature, $v_{2, \text { ex }}^{\mathrm{o}}$ has been found to be negative remaining almost constant in the temperature range studied.

The results on surface tension measurements of aqueous TFE are given in Table S3 and plotted in Fig. 3a. It is seen from Fig. 3a that the surface tension of aqueous TFE decreases non-linearly with increasing concentration of the alcohol. Therefore, slope of the plot was obtained by measuring the tangent as a function of alcohol concentration.

\section{Discussion}

\subsection{Differential scanning calorimetry of lysozyme in presence of TFE}

The thermal transitions of lysozyme were reversible and the average $\beta$ value (ratio of van't Hoff to calorimetric enthalpy) in all the experiments

Table 6

The density, partial molecular volume $\left(v_{2}^{\mathrm{o}}\right)$ molecular volume $\left(v_{2}\right)$ and excess molecular volume $\left(v_{2, \mathrm{ex}}^{\mathrm{o}}\right)$ of aqueous TFE at different temperatures

\begin{tabular}{|c|c|c|c|c|}
\hline $\begin{array}{l}\text { Temperature } \\
(\mathrm{K})\end{array}$ & $\begin{array}{l}\text { Density } \\
\left(\mathrm{g} \mathrm{cm}^{-3}\right)\end{array}$ & $\begin{array}{l}v_{2}^{\mathrm{o}} \times 10^{-23} \\
\left(\mathrm{~cm}^{3} \text { molecule }{ }^{-1}\right)\end{array}$ & $\begin{array}{l}\boldsymbol{v}_{2} \times 10^{-23} \\
\left(\mathrm{~cm}^{3} \text { molecule }{ }^{-1}\right)\end{array}$ & $\begin{array}{l}v_{2, \mathrm{ex}}^{\mathrm{o}} \times 10^{-23} \\
\left(\mathrm{~cm}^{3} \text { molecule }{ }^{-1}\right)\end{array}$ \\
\hline 283.11 & 1.401534 & 10.76 & 11.85 & -1.09 \\
\hline 288.11 & 1.393534 & 10.81 & 11.91 & -1.10 \\
\hline 298.15 & 1.377470 & 10.94 & 12.05 & -1.11 \\
\hline 308.19 & 1.361406 & 11.07 & 12.20 & -1.13 \\
\hline
\end{tabular}




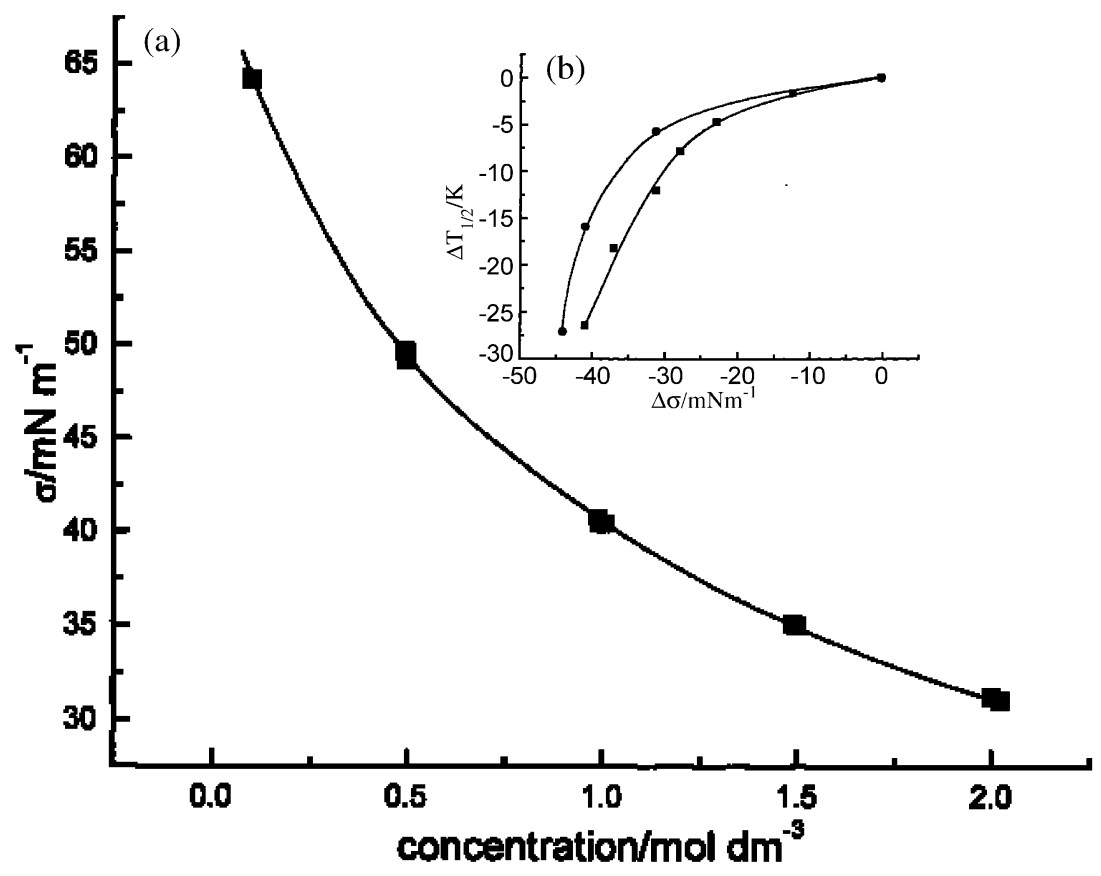

Fig. 3. (a) Surface tension plotted against molality of aqueous 2,2,2-trifluoroethanol at $298.15 \mathrm{~K}$. (b) Plot of change in thermal stability of lysozyme (O) and $\alpha$-lactalbumin ( $\mathbf{a})$ against the change in surface tension of water in the presence of TFE. The data on $t_{1 / 2}$ of $\alpha$-lactalbumin have been taken from our earlier measurements [26].

was $1.01 \pm 0.02$ indicating that thermal unfolding of lysozyme under these conditions follows Native $(\mathrm{N}) \rightleftharpoons$ Denatured (D) mechanism. Fig. 1 shows that destabilizing ability of TFE varies with $\mathrm{pH}$. But $\Delta T_{1 / 2}\left[\left(T_{1 / 2}\right.\right.$ of in presence of cosolvent$T_{1 / 2}$ in buffer)] plotted against the concentration of TFE is pH independent (Fig. 2a). It is because at three different $\mathrm{pH}$ values lysozyme has different $T_{1 / 2}$ in the native state but the relative lowering of transition temperature by TFE is same. This indicates that the charge on lysozyme in general is not affecting the destabilizing capability of TFE. It is observed in Table 2 that at a particular $\mathrm{pH}$, the $\Delta \nu$ values at all the concentrations of TFE are same, suggesting that the effect of increasing concentration of TFE does not influence abstraction or release of proton in the amino acid residues of lysozyme. However, at different $\mathrm{pH}$ and in same concentration of TFE the extent of abstraction or release of proton changes. But this effect is not significant since $\Delta T_{1 / 2}$ remains the same. The possible explanation may lie in the observation that the number of charged amino acid residues in lysozyme is only $18 \%$ of the total 129 amino acid residues of lysozyme. Hence charge effect does not play an important role in its interaction with TFE, and the ionization constants of the amino acid side chains do not vary appreciably under the studied concentration range of TFE. The buffers used here do not modulate experimental observations appreciably because the enthalpies of ionization of glycine- $\mathrm{HCl}$ and acetate-acetic acid [38] are 4.0 and $0.41 \mathrm{~kJ} \mathrm{~mol}^{-1}$, respectively, which are very small compared to the enthalpies of denaturation of lysozyme (Table 1). Also, the ionization effects of the groups of lysozyme being titrated in this $\mathrm{pH}$ range are partly compensated by ionization effects of glycine and acetate buffers [39]. Hence no corrections were applied to the observed enthalpies to reflect buffer ionization heats caused by these proton transfers.

The values of $\Delta \Gamma_{23}$ were found to be positive (Fig. 2b) indicating that unfolding of the protein leads to a state with a larger affinity to component 
3 (additive) than that in the native state. From the figure it is clear that the denaturational change in the preferential solvation of the protein is independent of the $\mathrm{pH}$, supporting the calorimetric results that the charge on the protein does not affect its interaction with TFE appreciably.

\subsection{Apparent molar volumes of amino acids and peptides in $1 \mathrm{~mol} \mathrm{dm} \mathrm{m}^{-3}$ TFE and their partial molar volume of transfer from water to $1 \mathrm{~mol}$ $d m^{-3}$ TFE}

The molality dependence of $V_{\phi, 2}$ can be interpreted in terms of solute-solute interactions. The sign of $S_{v}$ value is determined by the nature of interactions between the solute species. The overlap of the solvent co-spheres when two charged centers such as zwitter-ionic end groups $-\mathrm{NH}_{3}^{+}$ and $-\mathrm{COO}^{-}$interact in solution results in a positive volume change as some electrostricted water is returned to the bulk solvent. However, the overlap of two hydrophobic hydration cospheres when apolar groups interact leads to a negative volume change leading to a negative $S_{v}$ value. For zwitterionic glycine, aspartic acid and lysine the positive values of $S_{v}$ suggest that solute-solute interaction as a function of molality is dominated by the interaction of the charged functional groups. The much larger values of $S_{v}$ for ionic aspartic acid and lysine compared to glycine is another proof of it.

The volume of transfer results can be explained on the basis of co-sphere overlap model developed by Gurney [40] and by Frank and Evans [41]. Properties of the water molecules in the hydration co-sphere of the solute depend upon the nature of the solute species. TFE is approximately four times larger than a water molecule. The presence of $-\mathrm{CF}_{3}$ group indicates a degree of hydrophobic character that is supported by much lower solvation free energy of methane in TFE compared to water. It is also reported that inductive effect of the fluoro substituents increases the acidity of the hydroxyl proton in comparison with ethanol, thus making it a better hydrogen bond donor but a poorer hydrogen bond acceptor [42]. The types of interactions that can occur between TFE and the amino acids and peptides can be classified as: (i) hydrophilic-ionic group interactions between $-\mathrm{OH}$ group of the alcohol and the polar/zwitterionic centers of the amino acids or peptides, (ii) hydrophilic-hydrophilic group interactions between the $-\mathrm{OH}$ group of TFE and -CONH group of the peptides, (iii) hydrophobic-ionic/hydrophilic group interactions between $-\mathrm{CF}_{3}$ group of TFE and polar/zwitter ionic centers of the amino acids or peptides or with the -CONH group of the peptides, (iv) hydrophobic-hydrophobic group interactions between $-\mathrm{CF}_{3}$ group of TFE and the non-polar $-\mathrm{CH}_{2}$ groups of the amino and peptides. Interactions of type (i) lead to a positive contribution to $V_{2, m}^{\mathrm{o}}(\mathrm{tr})$ since the overlap of the hydration cospheres of the $-\mathrm{NH}_{3}^{+}$and $-\mathrm{COO}^{-}$groups, and $-\mathrm{OH}$ group of the alcohol, the structure breaking tendency of the ions and hence the electrostriction of the solvent caused by these ions are reduced. Hence, some water molecules go back to their normal structure leading to an increase in volume. Also, the direct interactions between the zwitterionic and hydroxy groups via hydrogen-bonded network of water also contribute positively to the volume. Interactions of type (ii) also make a positive contribution to $V_{2, m}^{\mathrm{o}}(\mathrm{tr})$ since the overlap of the hydration cospheres of $-\mathrm{OH}$ and $-\mathrm{CONH}$ groups should lead to an increase in the magnitude of the hydrogen-bonding interactions. However, the interactions between the hydrophobic $-\mathrm{CF}_{3}$ and zwitterionic or - $\mathrm{CONH}$ groups leads to a decrease in $V_{2, m}^{\mathrm{o}}(\mathrm{tr})$ values because of reduction of water structure that is formed around these groups as a result of their cosphere overlap.

The $V_{2, m}^{\mathrm{o}}(\mathrm{tr})$ values for glycine and serine from water to $1 \mathrm{~mol} \mathrm{dm}^{-3}$ TFE are found to be similar. This similarity in the $V_{2, m}^{\mathrm{o}}(\mathrm{tr})$ values of glycine and serine is due to the balancing effect of the hydrophobic $-\mathrm{CH}_{2}$ moiety and the hydrophilic $-\mathrm{OH}$ group. Amongst the amino acids studied, valine, aspartic acid and lysine show a negative volume of transfer. The $-\mathrm{CH}\left(\mathrm{CH}_{3}\right)_{2}$ group in valine leads to an increase in hydrophobic-hydrophilic group interactions between the hydrophobic side chain of the amino acid and $-\mathrm{OH}$ group of the alcohol contributing negatively to the volume of transfer. The interaction between this $-\mathrm{CH}\left(\mathrm{CH}_{3}\right)_{2}$ group and the hydrophobic $-\mathrm{CF}_{3}$ group also contributes negatively to $V_{2, m}^{\mathrm{o}}(\mathrm{tr})$. The 
value of $V_{2, m}^{\mathrm{o}}(\mathrm{tr})$ for both the charged amino acids is negative. This indicates that the effect of hydrophobic $-\mathrm{CH}_{2}-$ groups in aspartic acid and lysine overweighs the effect of additional hydrophillic $-\mathrm{COO}^{-}$group interactions. Higher negative value of $V_{2, m}^{\mathrm{o}}(\mathrm{tr})$ for lysine can be assigned to more hydrophobic $-\left(\mathrm{CH}_{2}\right)_{4}-$ group which leads to an enhanced hydrophobic-hydrophilic and hydrophobic-hydrophobic group interactions between solute and solvent molecules. The results obtained in this study on amino acids indicate that the interaction of hydrophobic groups in the amino acids with $-\mathrm{CF}_{3}$ and $-\mathrm{OH}$ group in TFE dominates over the interaction of the ionic and hydrophilic groups of the amino acids with $-\mathrm{OH}$ group of the alcohol. This is based upon the observation that the $V_{2, m}^{\mathrm{o}}(\mathrm{tr})$ value of the amino acids is either very small within the standard deviation or negative.

The experiments were done with diglycine and triglycine to study the effect of aqueous TFE on the peptide bonds. It is seen in Table 3 that the volume of transfer increases from glycine to diglycine to triglycine. The interaction of the $-\mathrm{OH}$ group of alcohol with the peptide group dominates over the hydrophobic-hydrophobic interactions between the increased $-\mathrm{CH}_{2}$ groups in the peptide and the $-\mathrm{CF}_{3}$ group of alcohol, leading to more positive values of $V_{2, m, \text { tr }}^{\mathrm{o}}$ in the case of triglycine compared to diglycine and glycine. The results on glycine peptides indicate that aqueous TFE forms a cosolvent system in which the exposed peptide groups have a tendency to interact favorably with the $-\mathrm{OH}$ group of the alcohol. The enhanced preferential interactions of the hydrophobic groups in the denatured state of the protein with the hydrophobic $-\mathrm{CF}_{3}$ group of TFE, and between the peptide groups of the protein with the $-\mathrm{OH}$ groups of the alcohol shifts the Native $\rightleftharpoons$ Denatured equilibrium to the right, thus lowering the thermal stability of the protein.

\subsection{Physico chemical properties of aqueous TFE and correlation to thermal unfolding of lysozyme}

The value of apparent molar heat capacity $\left(C_{p, \phi, 2}\right)$ and apparent molar volume $\left(V_{\phi, 2}\right)$ gives an idea about the structural changes taking place in water in presence of the cosolvent. The values of $C_{p, \phi, 2}$ decreased with increasing temperature but the dependence was not significant. It has been shown on a large number of model compounds in the temperature range from 5 to $150{ }^{\circ} \mathrm{C}$, that the partial molar heat capacity of non-polar compounds monotonically decreases with an increase of temperature [43]. The $C_{p, \phi, 2}$ values of aqueous TFE show a sudden fall beyond a molality of $1.57806 \mathrm{~mol} \mathrm{~kg}^{-1}$ (mole fraction of 0.031 ) at a given temperature. Aggregation of TFE molecules in TFE-water mixtures has been observed by Xray scattering and NMR experiments $[44,45]$. The degree of aggregation is also reported to be composition-dependent with a maximum of approximately 0.1 mole fraction of TFE [45]. The fall in the apparent molar heat capacity of the aqueous TFE beyond $1.57806 \mathrm{~mol} \mathrm{~kg}^{-1}$ can be assigned to the increase in the association of TFE in water.

The relative light-scattering intensities of aqueous TFE were measured at a scattering angle of $90^{\circ}$ by Gast et al. [7]. They observed that up to a mole fraction of 0.056 , the scattering intensity does not change appreciably. It was suggested that TFE-water mixtures at $293 \mathrm{~K}$ behave like ideal solutions up to a mole fraction of 0.056 . The highest mole fraction of aqueous TFE used in volumetric measurements is 0.010 ; hence a concentration independent behavior of aqueous TFE is consistent with their observations.

Quantitative information on hydration of solutes can be obtained from the thermal expansion of aqueous solution using the following equation,

$\left(\partial C_{p, 2}^{\mathrm{o}} / \partial p\right)_{T}=-T\left(\partial^{2} V_{2, m}^{\mathrm{o}} / \partial T^{2}\right)_{p}$.

It was suggested [46] that structure breaking solutes are accompanied by positive $\left(\partial C_{p, 2}^{\mathrm{o}} / \partial p\right)_{T}$ and negative $\left(\partial^{2} V_{2, m}^{o} / \partial T^{2}\right)_{p}$. Despite limitations, this qualitative classification is useful to distinguish between the ionic or polar solutes and for those in which hydrophobic hydration is dominant [46]. Arguments based upon 'structure making' and 'structure breaking' have contradictory reports $[47,48]$. Since the partial molar volume data fits well to the linear equation (correlation coefficient, $R=0.977)$, the value of $\left(\partial^{2} V_{2, m}^{\mathrm{o}} / \partial T^{2}\right)_{p}$ is negligibly small. Fitting the volumetric data to second degree polynomial did not improve the standard 
deviation. Therefore it can be concluded that aqueous TFE's structure altering the ability does not vary appreciably with the change in temperature.

The $v_{2, \text { ex }}^{\mathrm{o}}$ (Table 6) characterizes the volume change associated with the transfer of one molecule of pure TFE to an infinitely diluted solution, which involves a combination of the packing effect in solution and interaction with water leading to its structural changes. Since the change in the values of $v_{2, \text { ex }}^{o}$ with rise in temperature is very small $\left(-1.09\right.$ to $-1.13 \times 10^{-23} \mathrm{~cm}^{3}$ molecule $\left.{ }^{-1}\right)$, it further strengthens our conclusion from the negligibly small $\left(\partial^{2} V_{2, m}^{\mathrm{o}} / \partial T^{2}\right)_{P}$ results that the water structure making ability of TFE does not vary appreciably in the studied range (283.11$308.19 \mathrm{~K}$ ) of temperature.

When the system is at equilibrium, the surface chemical potentials of all components must be equal to their chemical potentials in the bulk phase. If the surface tension of the solvent is perturbed by the addition of a component, its concentration in the surface layer must differ from that in the bulk solution. It has been observed that alteration in the surface tension of water in the presence of co-solvents of varying properties plays a major role in the stabilization of proteins in aqueous solutions and their preferential hydration. Timasheff [49] has shown that several compounds that raise the surface tension of water, lead to preferential exclusion of the co-solvent from the surface of the protein. Preferential exclusion is the depletion of the co-solvent molecules in the interface leading to their deficiency in the vicinity of the protein, and excess of water over the bulk solvent composition. The excess amount of the $i$ th component per unit area of surface is given by the Gibbs Adsorbtion Isotherm [50]

$\Gamma_{i}=\frac{n_{i}^{*}}{s}=-\left(\frac{\partial \sigma}{\partial \mu_{i}}\right)_{T}=-\frac{a_{i}}{R T} \cdot\left(\frac{\partial \sigma}{\partial a_{i}}\right)_{T}$

where $a_{i}$ is the activity of the component $i$ and $s$ is the surface area of the protein. $n_{i}^{*}$ is a measure

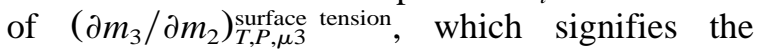
change in the concentration of ligand in the domain of protein required to restore chemical equilibrium. Here $m_{2}, m_{3}, \mu_{3}, a_{3}, \sigma, s, T, P$ and $R$ are, respectively, the molality of protein, molality of co-solvent, chemical potential of co-solvent, activity of co-solvent, surface tension, molar surface area of the protein, temperature, pressure and gas constant. Assuming that the protein-solvent interface is chemically inert, the exclusion of water by perturbation of the surface free energy can be calculated as:

$\left(\frac{\partial m_{3}}{\partial m_{2}}\right)_{T, P, \mu 3}^{\text {surface-tension }}=-\frac{s a_{3}}{R T}\left(\frac{\partial \sigma}{\partial a_{3}}\right)_{T, p}$

Here, surface tension in the superscript indicates that the binding parameter has been calculated from surface tension measurements and hence the values of $\left(\partial m_{3} / \partial m_{2}\right)_{T, P, \mu 3}$ represent only a relative picture. According to Eq. (9), the compounds that lead to a positive increase in the surface tension of water with an increasing concentration of the co-solvent, should give a negative binding parameter $\left(\partial m_{3} / \partial m_{2}\right)_{T, P, \mu 3}$ and hence lead to the preferential exclusion of the co-solvent molecules from the protein surface. The binding parameter for the interaction of TFE with lysozyme was calculated by using Eq. (9), surface tension data obtained by us, and the surface area of lysozyme, taken from literature $\left(0.6844 \times 10^{-16} \mathrm{~m}^{2}\right)$ [21]. The binding parameter $\left(n_{i}^{*}\right)$ gives the excess number of cosolvent molecules near the vicinity of the protein in the native state. The change in the preferential solvation $\left(\Delta \Gamma_{23}\right)$ gives an excess number of cosolvent molecules near the protein in the denatured state, relative to the native state. For $1 \mathrm{~mol} \mathrm{dm}^{-3}$ TFE at $\mathrm{pH} 2.4$ both the parameters were calculated and it was found that in the native state the number of molecules in relative excess of water near the protein is 285 and after denaturation, the relative change to the number of TFE molecules is 3.2 mol of TFE $/ \mathrm{mol}$ of protein. The positive values of $\Delta \Gamma_{23}$ (Fig. 2a) suggest that the TFE molecules interact more with the denatured state. A molecular dynamic study of TFE as a cosolvent on the stability of three different secondary structureforming peptides has been reported [51]. The simulations suggest that the stabilizing effect of TFE is induced by the preferential aggregation of TFE molecules around the peptides.

Fig. $3 b$ represents the drop in transition temperature of the homologous proteins hen egg-white 


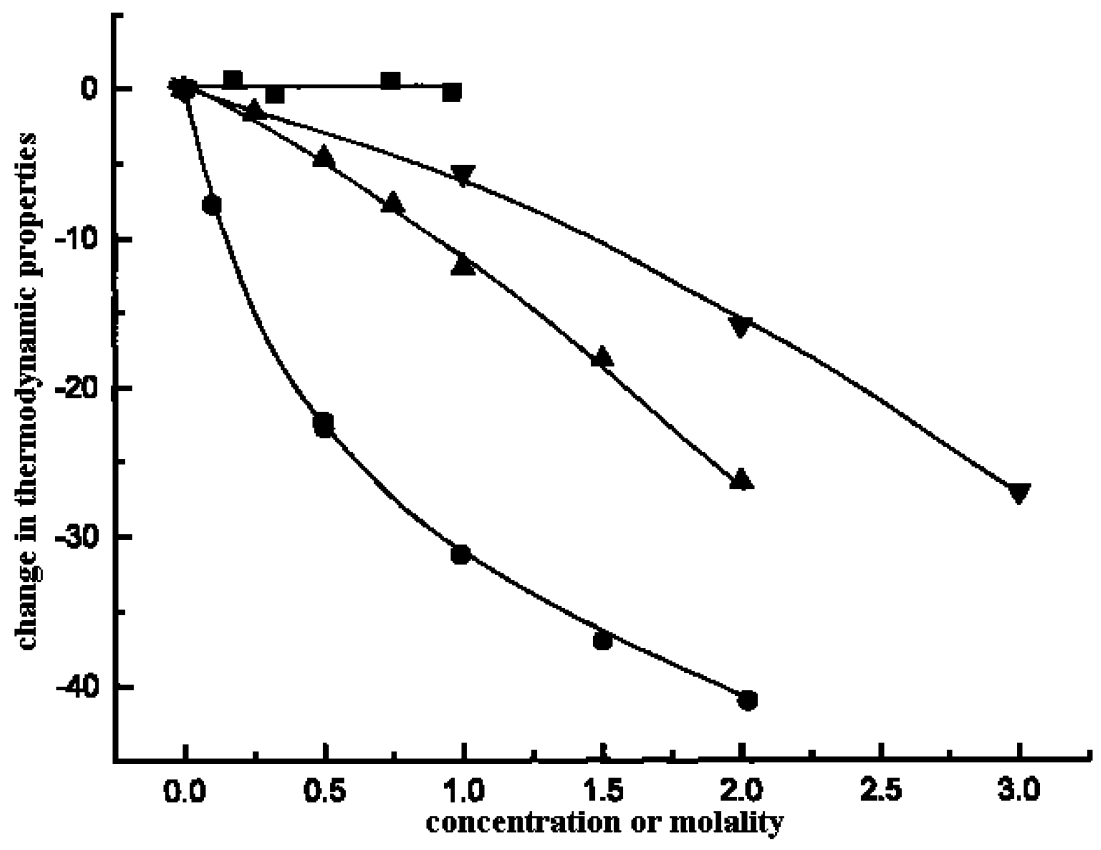

Fig. 4. Plot of change in thermodynamic properties against concentration or molality of cosolvent: volume $\left\{\mathbf{\square}, \Delta V /\left(\mathrm{cm}^{3} \mathrm{~mol}{ }^{-1}\right)=\right.$ $V_{\phi, 2}$ (aqueous TFE) $-V_{2, m}^{\mathrm{o}}$ (aqueous TFE) $\}$, surface tension $\left\{\boldsymbol{Q}, \Delta \sigma /\left(\mathrm{mN} \mathrm{m}^{-1}\right)=\sigma(\right.$ aqueous TFE $)-\sigma($ water $\left.)\right\}$, and transition temperature of protein $\left\{\Delta t_{1 / 2} / \mathrm{K}=t_{1 / 2}\right.$ (protein $\left.+\mathrm{TFE}\right)-t_{1 / 2}$ (protein in buffer); $\boldsymbol{\Delta}$, lysozyme; $\mathbf{\nabla}, \alpha$-lactalbumin. (The data on $t_{1 / 2}$ of $\alpha$-lactalbumin have been taken from earlier measurements in our laboratory [26].) The abscissa represents molality in mol $\mathrm{kg}^{-1}$ for

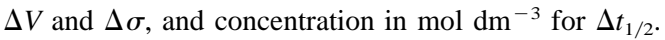

lysozyme and $\alpha$-lactalbumin [26] in the presence of TFE as a function of the fall in the surface tension of water at $298.15 \mathrm{~K}$. It shows a nonlinear and non-overlapping correlation. The effect of variation of the molality of TFE on apparent molar volume, surface tension, and transition temperature of lysozyme and $\alpha$-lactalbumin [26] are compared in Fig. 4. The plot of $\Delta V_{\phi}$ is parallel to the molality axis indicating that the solute-solute interaction does not have correlations with its effect on the TFE-protein interaction. The values of $C_{p, \phi, 2}$ for aqueous TFE also do not change appreciably upto a molality of $1.57806 \mathrm{~mol} \mathrm{~kg}-1$ beyond which there is a fall due to aggregation of the alcohol. However, this aggregation of the alcohol does not lead to any abrupt change in the thermal destabilization of the protein that follows a uniform non-linear trend with increasing concentration of the alcohol (Fig. 4). The results obtained in this study show that TFE leads to a considerable decrease in the surface tension of water. This fall in the surface tension correlates well with the decrease in the thermal stability of the proteins (Fig. 4). The comparison of the data on the thermal denaturation of hen egg-white lysozyme and $\alpha$ lactalbumin in presence of TFE indicate that TFE is more effective destabilizer of the native structure of $\alpha$-lactalbumin than egg-white lysozyme. This is due to the looser structure of $\alpha$-lactalbumin than lysozyme.

Fig. $3 b$ and Fig. 4 suggest that the surface tension appears to be a major force in governing the lysozyme-TFE interaction leading to the destabilization of the protein molecule. Two operative forces have been considered to be contributing to the increased thermal stability in a solvent of high surface energy: (i) an increased energy required for cavity formation, [52] and (ii) preferential hydration of the protein [53]. The decreased surface tension of water in the presence of TFE leads 
to a preferential exclusion of water molecules from the vicinity of protein and destabilizing the protein by disrupting the stabilizing interaction that protein had with the surrounding water.

Hydrophobic interactions are dominant in determining the stability in proteins hence their disruption destabilizes the compact native state, favoring the extended non-compact state. From light scattering measurements it has been reported that globular proteins increase in size upon unfolding [54]. As the surface energy of the surrounding solvent is decreased in the presence of TFE, the energy required to form the cavity to accommodate the non-native state is also less. Thus, the net free energy of stabilization or destabilization depends upon the free energy of cavity formation in a solvent of given surface free energy and the free energy contribution from protein-solvent interactions:

$$
\Delta \Delta G^{\mathrm{o}}=\Delta \Delta G_{\text {cavitation }}^{\mathrm{o}}+\Delta \Delta G_{\text {solvation }}^{\mathrm{o}} .
$$

Since TFE is observed to be a strong denaturant of lysozyme, both the surface tension and preferential interaction of the alcohol play a dominant role in this case.

Although surface tension is measured at a flat homogeneous air-water interface, the protein surface is neither flat nor chemically homogeneous. The protein surface that the solvent will experience will have sections varying in polarity, hydrophobicity and electric charges. The co-solute molecules may have preference for a particular loci on the surface and this may lead to binding. Hence binding of TFE to the side chain of the protein, even if weak, may be present as the molecule has a hydrophobic $\mathrm{CF}_{3}$ part and a ploar $-\mathrm{OH}$ group. The non-overlapping nature of the variation of the surface tension and the transition temperature, though in the same direction (Fig. 3b and Fig. 4) indicates involvement of other factors apart from surface tension effect, like binding in the TFEprotein interaction. Though our present study do not probe into the probable binding phenomena.

\subsection{Mode of interaction of TFE}

Our work shows that after the addition of TFE to the protein solution, the TFE molecule replaces water from the surrounding of the protein, thereby interacting with the amino acid residues and peptide bonds in the protein as explained earlier by the overlap of their hydration co-spheres and positive $\Delta \Gamma_{23}$ values. As in the denatured state the amino acid residues and peptide groups are more exposed to the solvent, hence the denatured state preferentially interacts with TFE molecules causing a shift in the $\mathrm{N} \rightleftharpoons \mathrm{D}$ equilibrium to right as reflected by the decrease in transition temperature of the protein. The decreased surface energy required for cavity formation facilitates the process.

Two classes of mechanisms have been reported in literature. One is the direct binding of TFE molecules to the protein. In a study with five peptide homologues, it was proposed that TFE preferentially associates with the helical conformer, replacing the water molecules [15]. Study with ethanol and lysozyme has been reported in which the ethanol molecules replace water molecules in lysozyme, [55] but TFE being much larger in size than ethanol, it may not be logical to extrapolate the finding to TFE. Rajan and Balaram [16] also proposed the hypothesis for direct interaction of TFE with proteins. Accordingly, the fluorocarbon terminus of TFE should interact favorably with the hydrophobic side chains whereas the hydroxy terminus should interact with the amide carbonyls. Another direct mechanism involves selective stabilization of intramolecular hydrogen bonds by TFE [17]. The molecular dynamic study done by Roccatano et al. [51] have also suggested that the coating of TFE molecules displace water, thereby removing alternative hydrogen-bonding partners and providing a low dielectric environment that favors the formation of intrapeptide hydrogen bonds. A recent study on the system TFE and a tetradecapeptide Bombesin by NOE measurements show a complete surface covering of the molecule by TFE along with clustering of TFE molecule around the peptide [19].

The second proposal is the interaction through solvent mediated effect: in the mole fraction range of $0-0.15$, the addition of TFE to water makes the solvent environment less polar and hence the capacity of water to interact and stabilize amide functionality is impaired. Accordingly, the addition 
of TFE must disfavor any conformation that bears solvent exposed amide functions and hence TFE must favor compact states that have internally hydrogen bonded or solvent sequestered amide functions. Hence, it was proposed that TFE increases helicity by selectively raising the energy of solvent exposed amide functionality in the coil state [14]. Another model for indirect mechanism was reported [20] in which the random coil was chosen as the most solvated state and hence most perturbed by the addition of cosolvent. The helix formation is impeded by the entropic cost of assembling the aqueous solvent shell around the helix in pure water, addition of TFE thus favors the helix as $\mathrm{d} \Delta S / \mathrm{d}[\mathrm{TFE}]>0$. According to Jackson and Mantsch [56], the ability of halogen alcohols to induce helices is primarily due to the properties of the solvent. The high dipole moment of these alcohols disrupts the hydrogen-bonding scheme within the protein and the low dielectric constant induces helix formation.

Our work shows that the mechanism of TFEprotein interaction includes a combination of both solvent mediated effect and direct interaction.

\section{Acknowledgments}

This work has been sponsored by the Department of Science and Technology, New Delhi, India. AK is supported by a fellowship from CSIR, Delhi.

\section{References}

[1] M. Goodman, I. Listowsky, Conformational aspects of synthetic polypeptides. VI Hypochromic spectral studies of oligo- $\gamma$-methyl-L-glutamate peptides, J. Am. Chem. Soc. 84 (1962) 3770-3771.

[2] M. Hoshino, Y. Hagihara, D. Hamada, M. Kataoka, Y. Goto, Trifluoroethanol-induced conformational transition of hen egg-white lysozyme studied by small-angle X-ray scattering, FEBS Lett. 416 (1997) 72-76.

[3] J.K. Myers, C.N. Pace, J.M. Scholtz, Trifluoroethanol effects on helix propensity and electrostatic interactions in the helical peptide from ribonuclease T1, Protein Sci. 7 (1998) 383-388.

[4] Y. Luo, R.L. Baldwin, Trifluoroethanol stabilizes the $\mathrm{pH} 4$ folding intermediate of sperm whale apomyoglobin, J. Mol. Biol. 279 (1998) 49-57.

[5] G. Jayaraman, T.K.S. Kumar, A.I. Arunkumar, C. Yu, 2,2,2-Trifluoroethanol induces helical conformation in an all $\beta$-sheet protein, Biochem. Biophys. Res. Commun. 222 (1996) 33-37.

[6] F. Khan, R.H. Khan, S. Muzammil, Alcohol-induced vs. anion-induced states of $\alpha$-chymotrypsinogen $\mathrm{A}$ at low pH, Biochim. Biophys. Acta 1481 (2000) 229-236.

[7] K. Gast, D. Zirwer, M. Müller-Frohne, G. Damaschun, Trifluoroethanol-induced conformational transitions of proteins: insights gained from the differences between $\alpha$-lactalbumin and ribonuclease A, Protein Sci. 8 (1999) 625-634.

[8] M. Buck, S.E. Radford, C.M. Dobson, A partially folded state of hen egg white lysozyme in trifluoroethanol: structural characterization and implications for protein folding, Biochemistry 32 (1993) 669-678.

[9] O.B. Ptitsyn, R.H. Pain, G.V. Semisotnov, E. Zerovnik, O.I. Razgulyaev, Evidence for a molten globule state as a general intermediate in protein folding, FEBS Lett. 262 (1990) 20-24.

[10] S. Kumaran, R.P. Roy, Helix-enhancing propensity of fluoro and alkyl alcohols: influence of $\mathrm{pH}$, temperature and cosolvent concentration on the helical conformation of peptides, J. Peptide Res. 53 (1999) 284-293.

[11] Y. Fujita, A. Miyanaga, Y. Noda, Effect of alcohols on the thermal denaturation of lysozyme as measured by differential scanning calorimetry, Bull. Chem. Soc. Jpn. 52 (1979) 3659-3662.

[12] N. Schönbrunner, J. Wey, J. Engels, H. Georg, T. Kiefhaber, Native-like beta-structure in a trifluoroethanol-induced partially folded state of the all-beta-sheet protein tendamistat, J. Mol. Biol. 260 (1996) 432-445.

[13] A.I. Arunkumar, T.K. Kumar, C. Yu, Specificity of helix-induction by 2,2,2-trifluoroethanol in polypeptides, Int. J. Biol. Macromol. 21 (1997) 223-230.

[14] A. Cammers-Goodwin, T.J. Allen, S.L. Oslick, K.F. McClure, J.H. Lee, D.S. Kemp, Mechanism of stabilization of helical conformations of polypeptides by water containing trifluoroethanol, J. Am. Chem. Soc. 118 (1996) 3082-3091.

[15] A. Kentsis, T.R. Sosnick, Trifluoroethanol promotes helix formation by destabilizing backbone exposure: desolvation rather than native hydrogen bonding defines the kinetic pathway of dimeric coiled coil folding, Biochemistry 37 (1998) 14613-14622.

[16] R. Rajan, P. Balaram, A model for the interaction of trifluoroethanol with peptides and proteins, Int. J. Pept. Protein Res. 48 (1996) 328-336.

[17] A. Jasanoff, A.R. Fresht, Quantitative determination of helical propensities from trifluoroethanol titration curves, Biochemistry 33 (1994) 2129-2135.

[18] P. Luo, R.L. Baldwin, Mechanism of helix induction by trifluoroethanol: a framework for extrapolating the helix-forming properties of peptides from trifluoroethanol/water mixtures back to water, Biochemistry 36 (1997) 8413-8421.

[19] M. Dolores-Diaz, M. Fioroni, K. Burger, S. Berger, Evidence of complete hydrophobic coating of bombesin by trifluoroethanol in aqueous solution: an NMR spec- 
troscopic and molecular dynamics study, Chem. Eur. J. 8 (2002) 1663-1669.

[20] R Walgers, T.C. Lee, A. Cammers-Goodwin, An indirect chaotropic mechanism for the stabilization of helix conformation of peptides in aqueous trifluoroethanol and hexafluoro-2-propanol, J. Am. Chem. Soc. 120 (1998) 5073-5079.

[21] K.R. Acharya, D.I. Stuart, N.P.C. Walker, M. Lewis, D.C. Philips, Refined structure of baboon $\alpha$-lactalbumin at 1.7 A resolution. Comparison with C-type lysozyme, J. Mol. Biol. 208 (1989) 99-127.

[22] D. Martinez, J.T. Gerig, Intermolecular (1)H[(19)F] NOEs in studies of fluoroalcohol-induced conformations of peptides and proteins, J. Magn. Reson. 152 (2001) 269-275.

[23] L.V. Najbar, D.J. Craik, J.D. Wade, D. Salvatore, M.J. McLeish, Conformational analysis of Lys (11-36), a peptide derived from the beta-sheet region of T4 lysozyme, in TFE and SDS, Biochemistry 36 (1997) 11525-11533.

[24] B. Lai, A. Cao, L. Lai, Organic cosolvents and hen egg white lysozyme folding, Biochim. Biophys. Acta 1543 (2000) 115-122.

[25] F.E. Jones, The air density equation and the transfer of the mass unit, J. Res. Natl. Bur. Stand. (U.S.) 83 (1978) 419-428.

[26] N. Kishore, B. Sabulal, Thermodynamics of the interaction of some chloro- and fluoro-substituted alcohols with bovine $\alpha$-lactalbumin, J. Chem. Soc. Faraday Trans. 94 (1998) 905-911.

[27] W.H. Kirchhoff, EXAM, US Department of Energy, Thermodynamics Division, National Institute of Standards and Technology, Gaithersburg, MD, USA.

[28] A. Kundu, N. Kishore, Apparent molar heat capacities and apparent molar volumes of aqueous nicotinamide at different temperatures, J. Solution Chem. 32 (2003) 703-717.

[29] D.G. Archer, Thermodynamic properties of the sodium chloride + water system. II. Thermodynamic properties of $\mathrm{NaCl}(\mathrm{aq}), \mathrm{NaCl} .2 \mathrm{H}_{2} \mathrm{O}(\mathrm{cr})$, and phase equilibria, J. Phys. Chem. Ref. Data 21 (1992) 793-829.

[30] S.K. Singh, N. Kishore, Partial molar volumes of transfer of some amino acids and peptides from water to 1 mol dm ${ }^{-3}$ aqueous sodium acetate, sodium sulfate, and sodium thiocyanate at $25{ }^{\circ} \mathrm{C}$, and correlation of the transfer parameters to the thermal stability of hen eggwhite lysozyme and $\alpha$-lactalbumin in the presence of these salts, J. Solution Chem. 32 (2003) 117-135.

[31] S. Kitamura, J.M. Sturtevant, A scanning calorimetric study of the thermal denaturation of the lysozyme of Phage T4 and the Arg 96 $\rightarrow$ His mutant form thereof, Biochemistry 28 (1989) 3788-3792.

[32] E.L. Kovrigin, S.A. Potekhin, Preferential solvation changes upon lysozyme heat denaturation in mixed solvents, Biochemistry 36 (1997) 9195-9199.

[33] G.R. Hedwig, J.F. Reading, T.H. Lilley, Aqueous solutions containing amino acids and peptides. 27. Partial molar heat capacities and partial molar volumes of some $N$-acetyl amino acid amides, some $N$-acetyl peptide amides and two peptides at $25{ }^{\circ} \mathrm{C}$, J. Chem. Soc. Faraday Trans. 87 (1991) 1751-1758.

[34] A.K. Mishra, J.C. Ahluwalia, Apparent molal volumes of amino acids, $\mathrm{N}$-acetylamino acids, and peptides in aqueous solutions, J. Phys. Chem. 88 (1984) 86-92.

[35] D.D. MacDonald, B. Dolan, J.B. Hyne, The influence of substituted alcohols on the temperature of maximum density of water, J. Solution Chem. 5 (1976) 405-416.

[36] G.I. Makhatadze, M.M. Lopez, P.L. Privalov, Heat capacities of protein functional groups, Biophys. Chem. 64 (1997) 93-101.

[37] M. Hackel, G.R. Hedwig, H.J. Hinz, The partial molar heat capacity and volume of the peptide backbone group of proteins in aqueous solution, Biophys. Chem. 73 (1998) 63-177.

[38] R.N. Goldberg, N. Kishore, R.M. Lennen, Thermodynamic quantities for the ionization reactions of buffers in water, CRC Handbook of Chemistry and Physics, CRC Press, Boca Raton, 2002, p. 7-12-7-14.

[39] P.L. Privalov, S.A. Potekhin, Scanning microcalorimetry in studying temperature-induced changes in proteins, Methods Enzymol. 131 (1986) 4-51.

[40] R.W. Gurney, Ionic Processes in Solution, McGraw Hill, New York, 1953.

[41] H.S. Frank, M.W. Evans, Free volume and entropy in condensed systems. III. Entropy in binary liquid mixtures; partial molal entropy in dilute solutions; structure and thermodynamics in aqueous electrolytes, J. Chem. Phys. 13 (1945) 507-532.

[42] R. Chitra, P.E. Smith, Properties of 2,2,2-trifluoroethanol and water mixtures, J. Chem. Phys. 114 (2001) 426-435.

[43] G.I. Makhatadze, P.L. Privalov, Heat capacity of alcohols in aqueous solutions in the temperature range from 5 to $125{ }^{\circ} \mathrm{C}$, J. Solution Chem. 18 (1989) 927-936.

[44] K.R. Harris, P.J. Newitt, Z.J. Derlacki, Alcohol tracer diffusion, density, NMR and FTIR studies of aqueous ethanol and 2,2,2-trifluoroethanol solutions at $25^{\circ} \mathrm{C}$, J. Chem. Soc. Faraday Trans. 94 (1998) 1963-1970.

[45] D.P. Hong, M. Hoshino, R. Kuboi, Y. Goto, Clustering of fluorine-substituted alcohols as a factor responsible for their marked effects on proteins and peptides, J. Am. Chem. Soc. 121 (1999) 8427-8433.

[46] P.J. Bernal, W.A. Van Hook, Apparent molar volumes, isobaric expansion coefficients, and isoentropic compressibilities, and their H/D isotope effects for some aqueous carbohydrate solutions, J. Chem. Thermodyn. 18 (1986) 955-968.

[47] K. Miyajima, M. Sawada, M. Nakagaki, Studies on aqueous solution of saccharides. II. Viscosity B-coefficients, apparent molar volumes and activity coefficients of D-glucose, maltose and maltotriose in aqueous solutions, Bull. Chem. Soc. Jpn. 56 (1983) 1954-1957. 
[48] J.L. Neal, D.A. Goring, Volume-temperature relationships of hydrophobic and hydrophilic nonelectrolytes in water, J. Phys. Chem. 74 (1970) 658-664.

[49] S.N. Timasheff, in: R.B. Gregory (Ed.), Preferential Interactions of Water and Cosolvents with Proteins: Protein-Solvent Interactions, Marcel Dekker Inc, New York, 1995, pp. 445-482.

[50] J. Dong, B.Z. Chowdhry, S.A. Leharne, Surface activity of poloxamines at the interfaces between air-water and hexane-water, Colloids Surf. A 212 (2003) 9-17.

[51] D. Roccatano, G. Colombo, M. Fioroni, A.E. Mark, Mechanism by which 2,2,2-trifluoroethanol/water mixtures stabilize secondary-structure formation in peptides: a molecular dynamics study, Proc. Natl. Acad. Sci. USA 99 (2002) 12179-12184.
[52] T.Y Lin, S.N. Timasheff, On the role of surface tension in the stabilization of globular proteins, Protein Sci. 5 (1996) 372-381

[53] T. Arakawa, S.N. Timasheff, Preferential interactions of proteins with salts in concentrated solutions, Biochemistry 21 (1982) 6545-6552.

[54] Y.O. Kamatari, S. Ohji, T. Konno, The compact and expanded denatured state conformations of apomyoglobin in the methanol-water solvent, Protein Sci. 8 (1999) 873-882.

[55] M.S. Lehmann, S.A. Mason, G.J. McIntyre, Study of ethanol-lysozyme interactions using neutron diffraction, Biochemistry 24 (1985) 5862-5869.

[56] M. Jackson, H.H. Mantsch, Halogenated alcohols as solvents for proteins: FTIR spectroscopic studies, Biochim. Biophys. Acta 1118 (1992) 139-143. 